\title{
Antioxidant Activity of Aspergillus fumigatus
}

\author{
Daljit Singh Arora and Priyanka Chandra \\ Microbial Technology Laboratory, Department of Microbiology, Guru Nanak Dev University, Amritsar 143005, India \\ Correspondence should be addressed to Daljit Singh Arora, daljit_02@yahoo.co.in
}

Received 14 January 2011; Accepted 21 February 2011

Academic Editors: H. Cerecetto and M. L. Ferrandiz

Copyright ( 2011 D. S. Arora and P. Chandra. This is an open access article distributed under the Creative Commons Attribution License, which permits unrestricted use, distribution, and reproduction in any medium, provided the original work is properly cited.

\begin{abstract}
The antioxidant activity of Aspergillus fumigatus was assayed by different procedures and correlated with its extracellular total phenolic contents. Different physio-chemical parameters were optimized to enhance the activity. The culture grown under stationary conditions for 10 days at $25^{\circ} \mathrm{C}$ at $\mathrm{pH} 7$ gave the best antioxidant activity. Statistical approaches demonstrated sucrose and $\mathrm{NaNO}_{3}$ to be the most suitable carbon and nitrogen sources, respectively. Response surface analysis showed 5\% sucrose, $0.05 \%$ $\mathrm{NaNO}_{3}$, and incubation temperature of $35^{\circ} \mathrm{C}$ to be the optimal conditions for best expression of antioxidant activity. Under these conditions, the antioxidant potential assayed through different procedures was $89.8 \%, 70.1 \%$, and $70.2 \%$ scavenging effect for DPPH radical, ferrous ion and nitric oxide ion, respectively. The reducing power showed an absorbance of 1.0 and FRAP assay revealed the activity of $60.5 \%$. Extracellular total phenolic content and antioxidant activity as assayed by different procedures positively correlated.
\end{abstract}

\section{Introduction}

Lipid peroxidation is a complex process occurring in aerobic cells and reflects the interaction between molecular oxygen and polyunsaturated fatty acids. Free radicals are known to take part in lipid peroxidation, which causes food deterioration, aging, and cancer promotion. Reactive oxygen species are also reported to be involved in asthma, inflammation, arthritis, neurodegeneration, Parkinson disease, vascular cardiac diseases, and diabetes [1]. Antioxidants act as radicalscavengers, and inhibit lipid peroxidation and other free radical-mediated processes; therefore, these are able to protect the human body from several diseases attributed to the reactions of radicals. Use of synthetic antioxidants to prevent free radical damage has been reported to involve toxic side effects thus necessitating the search for natural antioxidants and free radical scavengers [2].

In the past few years, natural antioxidants have generated considerable interest in preventive medicine and in the food industry. For the replacement of conventional synthetic antioxidants in food by natural products, medicinal plant extracts, spices, and mushrooms are considered to be a promising source [3]. Within these compounds, flavonoids and phenolic acids, phytochemicals with a large distribution in nature have been the object of a great number of studies of their antioxidative activity, which is mainly due to their capacity to act as free radical scavengers and/or as metal chelators [4]. In consequence, attention has been focused on the characterization of the antioxidant properties of products from several natural resources and isolation and identification of the constituents responsible for such activities.

Recently, fungi have emerged as the new sources of antioxidants in the form of their secondary metabolites $[5,6]$. Fungi are remarkably a diverse group including approximately 1.5 million species, which can potentially provide a wide variety of metabolites such as alkaloids, benzoquinones, flavanoids, phenols, steroids, terpenoids, tetralones, and xanthones [7]. They demonstrate variety of bioactivities along with antioxidant properties and function as varied as their structure. They are exploited in medicine and industry and considered to be potential sources of new therapeutic agents.

Some fungi were isolated from soil and screened for antioxidant activity [8] and one of the best soil isolates (Aspergillus fumigatus) was selected for further study. 
Numerous techniques are available to evaluate the antioxidant activities of a compound, and just one procedure cannot identify all possible mechanisms characterizing an antioxidant. The comprehensive evaluation using different tests has been important in assessing the antioxidant activity. Therefore, different complementary test systems such as 1,1-diphenyl-2-picryl hydrazyl free radical (DPPH) assay, reducing power, ferrous ion and nitric oxide ion scavenging activity, and ferric reducing antioxidant power (FRAP) assay were used to assess the antioxidant potential of $A$. fumigatus. Different statistical designs (one-factor-at-a-time classical approach, Plackett-Burman design and response surface methodology) were used to enhance its activity. An effort has been made to work out the correlation (if any) between antioxidant activity and extracellular total phenolic content.

\section{Materials and Methods}

2.1. Growth of Aspergillus fumigatus. Aspergillus fumigatus was isolated from soil of Attari area, Amritsar, Punjab, India $\left(31^{\circ} 37^{\prime} 59^{\prime \prime}\right.$ North, $74^{\circ} 51^{\prime} 56^{\prime \prime}$ East) and identified on the basis of standard protocol and the identity was confirmed by National Fungal Culture Collection of India, Agharkar Research Institute, Pune, India. To study the antioxidant potential, the fungus was grown on $50 \mathrm{~mL}$ Czapek dox's broth (sucrose 3\%, $\mathrm{NaNO}_{3} 0.2 \%, \mathrm{~K}_{2} \mathrm{HPO}_{4} 0.1 \%, \mathrm{MgSO}_{4}$ $0.05 \%, \mathrm{KCl} 0.05 \%, \mathrm{FeSO}_{4} 0.001 \%$ ). The medium was inoculated with two discs $(8 \mathrm{~mm})$ of fungal mycelia obtained from 6-7 days grown culture on yeast extract glucose agar plates. The growth was carried out under stationary conditions at $25^{\circ} \mathrm{C}$. After incubation of 10 days, the culture broth was centrifuged at $10,000 \mathrm{RPM}$ at $4^{\circ} \mathrm{C}$ for 10 minutes and filtered through Whatman filter paper number 1 and the filtrate so obtained was used for further analysis.

\subsection{Assay Procedures for Antioxidant Activity}

2.2.1. 1,1-Diphenyl-2-picryl hydrazyl (DPPH) Free Radicals Scavenging Assay. The scavenging activity for DPPH free radicals was measured according to Zhao et al. [9] with slight modifications. To $2 \mathrm{~mL}$ of distilled water, $1 \mathrm{~mL}$ of $0.1 \mathrm{mM}$ DPPH solution in ethanol and $0.5 \mathrm{~mL}$ of extract was added. The mixture was shaken vigorously and allowed to reach a steady state for $30 \mathrm{~min}$ at room temperature. Decolourization of DPPH was determined by measuring the decrease in absorbance at $517 \mathrm{~nm}$, and the DPPH radical scavenging effect was calculated according to the following equation:

$$
\% \text { scavenging rate }=\left[1-\frac{(A 1-A 2)}{A 0}\right] \times 100,
$$

where $A 0$ represents the absorbance of the control (DPPH without extract), $A 1$ represents the absorbance of the reaction mixture, and $A 2$ represents the absorbance without $\mathrm{DPPH}$ (DPPH was replaced by the same volume of distilled water).

2.2.2. Determination of Antioxidant Activity by Reducing Power Measurement. The reducing power of the extract was determined according to Chang et al. [10] with slight modifications. An aliquot of $0.5 \mathrm{~mL}$ extract was added to $0.1 \mathrm{~mL}$ of $1 \%$ potassium ferricyanide. After incubating the mixture at $50^{\circ} \mathrm{C}$ for $30 \mathrm{~min}$, during which ferricyanide was reduced to ferrocyanide, it was supplemented with $0.1 \mathrm{~mL}$ of $1 \%$ trichloroacetic acid and $0.1 \% \mathrm{FeCl}_{3}$ and left for $20 \mathrm{~min}$. Absorbance was read at $700 \mathrm{~nm}$ to determine the amount of ferric ferrocyanide (Prussian blue) formed. Higher absorbance of the reaction mixture indicates higher reducing power of the sample.

2.2.3. Determination of Antioxidant Activity by Ferric Reducing Antioxidant Power (FRAP) Assay. FRAP assay was carried out according to Othman et al. [11] by monitoring the reduction of $\mathrm{Fe}^{3+}$-tripyridyl triazine (TPTZ) to blue colored $\mathrm{Fe}^{2+}$-TPTZ. The FRAP reagent was prepared by mixing $300 \mathrm{mM}$ acetate buffer (pH 3.6), $10 \mathrm{mM}$ TPTZ, and $20 \mathrm{mM}$ ferric chloride in a ratio of $10: 1: 1$. The reaction mixture containing $2 \mathrm{~mL}$ of FRAP reagent, $0.5 \mathrm{~mL}$ of extract, and $1 \mathrm{~mL}$ of distilled water was incubated for $10 \mathrm{~min}$ and the absorbance measured at $593 \mathrm{~nm}$. Antioxidant potential of the sample was compared with the activity of $0.5 \mathrm{~mL}$ stock solution of $1 \mathrm{mg} / \mathrm{mL} \mathrm{FeSO}_{4}$.

2.2.4. Determination of Ferrous Ion Scavenging (Metal Chelating) Activity. The chelating activity of the extract for ferrous ions was measured according to Zhao et al. [9]. The reaction mixture containing $0.5 \mathrm{~mL}$ of extract, $1.6 \mathrm{~mL}$ of deionized water, $0.05 \mathrm{~mL}$ of $\mathrm{FeCl}_{2}(2 \mathrm{mM})$ and $0.1 \mathrm{~mL}$ of ferrozine $(5 \mathrm{mM})$ was incubated at $40^{\circ} \mathrm{C}$ for $10 \mathrm{~min}$ and the absorbance measured at $562 \mathrm{~nm}$. The chelating activity was calculated as

$$
\text { Chelating rate }=\left[1-\frac{(A 1-A 2)}{A 0}\right] \times 100,
$$

where $A 0$ represents the absorbance of the control (without extract) $A 1$ represents the absorbance of reaction mixture, and $A 2$ represents the absorbance without $\mathrm{FeCl}_{2}$.

2.2.5. Determination of Nitric Oxide (NO) Scavenging Activity. Nitric oxide production from sodium nitroprusside was measured according to Kang et al. [12]. An equal amount $(6 \mathrm{~mL})$ of sodium nitroprusside $(5 \mathrm{mM})$ solution was mixed with $6 \mathrm{~mL}$ of extract and incubated at $25^{\circ} \mathrm{C}$ for $180 \mathrm{~min}$. After every $30 \mathrm{~min}, 0.5 \mathrm{~mL}$ of the reaction mixture was mixed with an equal amount of Griess reagent (1\% sulphanilamide, $2 \%$ phosphoric acid, and $0.1 \%$ napthylethylene diamine dihydrochloride), and absorbance was taken at $546 \mathrm{~nm}$ and compared with absorbance of $1 \mathrm{mg} / \mathrm{mL}$ of standard solution (sodium nitrite) treated in the same way with Griess reagent.

2.2.6. Determination of Total Phenolic Contents (TPC). The total phenolic contents were determined colorimetrically using the Folin-Ciocalteau (FC) method according to Singleton et al. [13] with some modifications. Test sample $(0.5 \mathrm{~mL})$ was mixed with $0.2 \mathrm{~mL}$ of FC reagent and allowed to stand for $10 \mathrm{~min}$ to which $0.6 \mathrm{~mL}$ of $20 \%$ sodium carbonate was added and mixed completely. The reaction mixture was incubated 
at $40^{\circ} \mathrm{C}$ for $30 \mathrm{~min}$. Absorbance of the reaction mixture was measured at $765 \mathrm{~nm}$. Gallic acid was taken as standard.

\subsection{Optimization of Physiochemical and Nutritional Param-} eters. Different physiochemical and nutritional parameters were optimized for Aspergillus fumigatus to enhance their antioxidant potential. To see the effect of shaking on the antioxidant activity, the fungi were grown on Czapek dox's broth at shaking conditions at different RPM 100, 150, 200, and 250 at $25^{\circ} \mathrm{C}$ and compared with that of antioxidant potential under static conditions. Then, to monitor the antioxidant potential of fungi with respect to incubation period, the activity was monitored every 5th day up to 30 days of growth under static conditions. Further, the activity of Aspergillus fumigatus was checked in the culture broth obtained from the organisms grown at different temperatures $\left(20^{\circ} \mathrm{C}, 25^{\circ} \mathrm{C}, 30^{\circ} \mathrm{C}, 35^{\circ} \mathrm{C}, 40^{\circ} \mathrm{C}, 45^{\circ} \mathrm{C}\right)$ and $\mathrm{pH}$ values (2 to 11 ).

\subsubsection{Medium Optimization Using One-Factor-at-a-Time Classical Method}

(1) Screening of Different Carbon and Nitrogen Sources. To find out the best carbon source, sucrose in the Czapek dox's medium was replaced with the same concentration of one of the sugars (glucose, maltose, lactose, starch, and glycerol) and to work out the best nitrogen source, $\mathrm{NaNO}_{3}$ in Czapek dox's medium was substituted with one or the other inorganic nitrogen source $\left(\mathrm{KNO}_{3}, \mathrm{NH}_{4} \mathrm{NO}_{3}, \mathrm{NH}_{4} \mathrm{Cl}\right.$, $\left.\left(\mathrm{NH}_{4}\right)_{2} \mathrm{SO} 4,\left(\mathrm{NH}_{4}\right) \mathrm{HSO}_{4}\right)$ or nitrogen rich organic supplement (yeast extract, peptone, malt extract, urea, casein, soyabean meal).

\subsubsection{Statistical Optimization of the Medium}

(1) Plackett-Burman Experimental Design. The PlackettBurman experimental design is a valuable tool for the rapid evaluation of the effects of various medium components. Because this design is a preliminary optimization technique, which tests only two levels of each medium component, it cannot provide the optimal quantity of each component required in the medium. This technique, however, provides indications of how each component tends to affect the activity. The screening of most significant parameters affecting antioxidant potential was studied by the Plackett-Burman design. The 5 factors, which are components of Czapek dox's medium (sucrose, $\mathrm{NaNO}_{3}, \mathrm{~K}_{2} \mathrm{HPO}_{4}, \mathrm{KCl}$, and $\mathrm{MgSO}_{4}$ ) were examined. Total 14 tests were designed including 12 combinations and 2 repetitions at central point which contain different concentration of each factor and the effect of each factor was determined by the difference between the average of the + and - responses. The significance level of effect of each factor was determined by student's $t$ test. The most common mean of assessing significant value is the $P$ value which was also evaluated for each factor.

(2) Response Surface Methodology through Box-Behnken Designs. On the basis of results from screening of different carbon and nitrogen sources through one-factor-at-a-time classical method and different components by PlackettBurman design, sucrose and $\mathrm{NaNO}_{3}$ were found to be the best for antioxidant activity. Sucrose as carbon source, $\mathrm{NaNO}_{3}$ as nitrogen source and temperature were taken independent variables for the optimization by RSM using Box-Behnken designs of experiments. Each variable was studied at three levels $(-1,0,+1)$; for sucrose these were $5 \%$, $3 \%$, and $1 \% ; \mathrm{NaNO}_{3}: 0.05 \%, 0.2 \%$, and $0.35 \%$; temperature: $15^{\circ} \mathrm{C}, 25^{\circ} \mathrm{C}$ and $35^{\circ} \mathrm{C}$.

The experimental design included 17 flasks with five replicates having all the three variables at their central coded values. The DPPH assay, reducing power, ferrous ion scavenging activity, FRAP assay and, nitric oxide ion scavenging activity and their total phenolic contents was taken as responses $G_{(1-6)}$. The mathematical relationship of response $\mathrm{G}$ (for each parameter) and independent variable $X\left(X_{1}\right.$, Sucrose; $X_{2}, \mathrm{NaNO}_{3}$; and $X_{3}$, temperature) was calculated by the following quadratic model equation:

$$
\begin{aligned}
G_{(1-6)}= & \beta_{0}+\beta_{1} X_{1}+\beta_{2} X_{2}+\beta_{3} X_{3}+\beta_{11} X_{1}^{2}+\beta_{22} X_{2}^{2} \\
& +\beta_{33} X_{3}^{2}+\beta_{12} X_{1} X_{2}+\beta_{13} X_{1} X_{3}+\beta_{23} X_{2} X_{3},
\end{aligned}
$$

where $G$ is the predicted response; $\beta_{0}$, intercept; $\beta_{1}, \beta_{2}$, and $\beta_{3}$, linear coefficients; $\beta_{11}, \beta_{22}$, and $\beta_{33}$, squared coefficients and $\beta_{12}, \beta_{13}$, and $\beta_{23}$ interaction coefficients. MINITAB version 11 statistical software was used to obtain optimal working conditions and generate response surface graphs. Statistical analysis of experimental data was also performed using this software.

2.4. Thermostability of Antioxidant Bioactivity. To check the temperature sensitivity of the culture broth for antioxidant activity, it was subjected to $40^{\circ} \mathrm{C}, 60^{\circ} \mathrm{C}, 80^{\circ} \mathrm{C}$, and $100^{\circ} \mathrm{C}$ for one $\mathrm{h}$ and the heat treated broth was then assayed for the residual antioxidant activity.

2.5. Extraction with Different Organic Solvents. To work out the best organic solvent for extraction of bioactive component, the culture broth was treated with different solvents viz petroleum ether, chloroform, ethyl acetate, and butanol. Solvent extracted components were then evaporated to dryness in vaccuo and the resulting solids were reconstituted in methanol to get five times concentrated stock preparations which were then checked for their antioxidant potential by various assays.

2.6. Toxicity Tests. The culture broth used to assess the antioxidant activity was subject to Ames test by using Salmonella reverse mutation based on histidine dependence and mutations in S. typhimurium [14]. Cytotoxicity was tested by using 3-(4,5-dimethylthiazol-2-yl)-2,5-diphenyl tetrazolium bromide (MTT) method. The fungal extracts $(100 \mu \mathrm{L})$ were incubated with $1 \times 10^{5} \mathrm{RBCs} /$ well in 96-well ELISA plates for $24 \mathrm{~h}$. Then, $100 \mu \mathrm{L}$ MTT solution $(0.5 \%$, w/v) was added to each well and incubated further for $4 \mathrm{~h}$. After incubation, the supernatant was removed and $100 \mu \mathrm{L}$ DMSO was added to each well to dissolve the formazan crystals. The absorbance was measured at $590 \mathrm{~nm}$ using an 
automated microplate reader. The wells with untreated cells served as control [15].

\section{Results}

3.1. Comparison of Antioxidant Potential By Different Quantitative Methods. The different assay procedures demonstrated Aspergillus fumigatus to possess potent antioxidant activity. The fungus showed a good scavenging effect of $69 \%$ on DPPH radicals. The reducing power $(0.51)$ of culture broth was demonstrated by the reduction of $\mathrm{Fe}^{3+}$ to $\mathrm{Fe}^{2+}$. It also demonstrated effective ferric ion reduction based on FRAP assay and gave reduction rate of $45.2 \%$. In addition, the chelation activity for ferrous ion was assayed and the fungal extracts chelated $48.3 \%$ of ferrous ion. The percentage rate of scavenging nitric oxide ion of fungal extracts was $50.2 \%$.

3.2. Total Phenolic Contents. The TPC of Aspergillus fumigatus extract have been expressed as gallic acid equivalent (GAE), that is, mg gallic acid/mL culture. The Aspergillus fumigatus possessed high TPC $(5.68 \mathrm{mg} / \mathrm{mL})$, which is positively correlated with their antioxidant potential.

\subsection{Antioxidant Activity under Different Physiochemical Conditions}

3.3.1. Effect of Shaking Conditions. The experiments carried out to see the effect of shaking at different RPM demonstrated static culture to give better antioxidant yield in comparison to shake flask cultures, which resulted in steady decline in the activity with increase in RPM. The scavenging effect was $69 \%$ under static culture conditions while it was $62.3 \%$ on shake flask culture. Again, reducing potential was 0.51 under static conditions and 0.42 at shaking conditions. Ferric ion reduction was also more in static (45.2\%) than in shake cultures $(40.1 \%)$. Ferrous and nitric ion scavenging activity decreased under shaking condition and it was $48.3 \%$ and $50.2 \%$ under static conditions, respectively. TPC value was also high in static culture $(5.68 \mathrm{mg} / \mathrm{mL})$ as compared to shake culture $(4.2 \mathrm{mg} / \mathrm{mL})$. Thus, further optimization was carried out under static conditions.

3.3.2. Effect of Growth Period. The antioxidant potential as assayed by different procedures was best expressed on the 10 th day with the scavenging effect of $68.8 \%, 48.3 \%$, and $50.2 \%$ on DPPH, ferrous and NO ion, respectively, and $45.2 \%$ for ferric ion reduction. The antioxidant activity as assayed by various procedures and TPC remained more or less similar on 15th day and subsequently declined upto 30 days. The decline in the TPC correlated uniformly with the decline in the activity.

3.3.3. Effect of Temperature and $p H$. The antioxidant potential was best observed at $25^{\circ} \mathrm{C}$ and in between $\mathrm{pH}$ 5-7 with the scavenging effect of $69 \%, 48.8 \%$, and $50.7 \%$ on $\mathrm{DPPH}$, ferrous; NO ion, respectively, and $45.1 \%$ for ferric ion reduction. There was no significant loss in the antioxidant activity or TPC up to $35^{\circ} \mathrm{C}$ while activity decreased at $40^{\circ} \mathrm{C}$. Neither any antioxidant activity nor TPC could be detected at extreme $\mathrm{pH}$ values $(2,3,10,11$, and 12) by any of the methods as there was no fungal growth at these extreme conditions.

\subsubsection{Effect of Different Carbon and Nitrogen Sources on} Antioxidant Potential. Initially, to assess the antioxidant potential by various assay procedures, all the experimentation was done by growing Aspergillus fumigatus on Czapek dox's broth medium. In order to find the optimal carbon source, sucrose was replaced with different sugars. However, sucrose remained the best to support the maximum antioxidant activity and the order followed was sucrose $>$ dextrose $>$ maltose $>$ starch $>$ lactose $>$ glycerol. Sucrose was thus selected as carbon source for further experimentation (Table 1).

Similarly, $\mathrm{NaNO}_{3}$ turned out to be the best nitrogen source to support maximum antioxidant potential. Peptone and yeast extract were also good sources of nitrogen, while urea gave the poorest activity (Table 2). The antioxidant profile of Aspergillus fumigatus for different nitrogen sources remained the same irrespective of assay procedure adopted. $\mathrm{NO}$ ion scavenging activity was monitored up to $180 \mathrm{~min}$ which increased gradually with respect to time. However, data pertaining to $180 \mathrm{~min}$ is only shown.

The highest TPC yield was $5.68 \mathrm{mg} / \mathrm{mL}$ in the presence of sucrose and $\mathrm{NaNO}_{3}$ in the medium. On the basis of the above results, Czapek dox's broth medium was chosen for the remaining experiments.

\subsection{Statistical Optimization of the Medium}

3.4.1. Plackett-Burman Design for Selection of Significant Components. A Plackett-Burman design experiment was employed to evaluate the influence of five factors (sucrose, $\mathrm{NaNO}_{3}, \mathrm{~K}_{2} \mathrm{HPO}_{4}, \mathrm{KCl}$, and $\mathrm{MgSO}_{4}$ ) and their importance in culture medium to obtain better antioxidant activity. Antioxidant potential of Aspergillus fumigatus assayed by different procedures and extracellularly produced total phenolic content that varied significantly with the 14 run of different combinations of the media components (Table 3 ). The maximum antioxidant potential along with high TPC was observed in run order 13 and run order 14 which was followed by run order 5 . The results were subjected to regression analysis and the analysis of variance (ANOVA) which revealed sucrose and $\mathrm{NaNO}_{3}$ to have statistically significant effect on antioxidant potential with $P$ value $\leq .05$ and $\leq .5$, respectively, thus showing that of the five variables, only sucrose and $\mathrm{NaNO}_{3}$ played a critical role for antioxidant activity. Based on these results, sucrose and $\mathrm{NaNO}_{3}$ were selected as two variables to optimize the medium composition by RSM. To know the optimum temperature and its interaction with other variables (sucrose and $\mathrm{NaNO}_{3}$ ), it was chosen as a third variable as it is an important physical parameter that affects the activity as well as fungal growth. 


\subsubsection{Box-Behnken Design}

(1) Fitting the Model. The data obtained from quadratic model equation was found to be significant. It was verified by $F$ value and the analysis of variance (ANOVA) by fitting the data of all independent observations in response surface quadratic model. The results for model $F$-value implies that the model is significant which indicates it to be suitable to represent adequately the real relationship among the parameters used. $R^{2}$ value for all the responses ranged between 82 to $87 \%$, which showed suitable fitting of the model in the designed experiments (Table 4). The final predictive equations for each response: DPPH assay $\left(G_{1}\right)$, reducing power $\left(G_{2}\right)$, ferrous ion scavenging activity $\left(G_{3}\right)$, FRAP assay $\left(G_{4}\right)$, and nitric oxide ion scavenging activity $\left(G_{5}\right)$ and their total phenolic contents $\left(G_{6}\right)$ obtained are as follow:

$G_{(1)}$

$$
\begin{aligned}
= & 12.19+22.55 X_{1}+93.48 X_{2}+0.37 X_{3}-2.38 X_{1}^{2}+132.56 X_{2}^{2} \\
& -0.0 X_{3}^{2}-51.08 X_{1} X_{2}+0.08 X_{1} X_{3}-0.17 X_{2} X_{3},
\end{aligned}
$$

$G_{(2)}$

$$
\begin{aligned}
= & 0.647+0.104 X_{1}+0.65 X_{2}-0.033 X_{3}-0.006 X_{1}^{2}+2.78 X_{2}^{2} \\
& -0.0006 X_{3}^{2}-0.66 X_{1} X_{2}+0.0033 X_{1} X_{3}+0.005 X_{2} X_{3},
\end{aligned}
$$

$G_{(3)}$

$$
\begin{aligned}
= & 3.69+14.24 X_{1}+78.73 X_{2}+0.60 X_{3}-1.22 X_{1}^{2}+185.67 X_{2}^{2} \\
& -0.0 X_{3}^{2}-50.17 X_{1} X_{2}+0.13 X_{1} X_{3}-0.42 X_{2} X_{3},
\end{aligned}
$$

$G_{(4)}$

$$
\begin{aligned}
= & 5.02+14.48 X_{1}+74.86 X_{2}+0.32 X_{3}-1.12 X_{1}^{2}+222.4 X_{2}^{2} \\
& +0.0 X_{3}^{2}-54.17 X_{1} X_{2}+0.12 X_{1} X_{3}-0.35 X_{2} X_{3},
\end{aligned}
$$

$G_{(5)}$

$$
\begin{aligned}
= & 5.58+14.20 X_{1}+75.93 X_{2}+0.69 X_{3}-1.18 X_{1}^{2}+201.0 X_{2}^{2} \\
& -0.0 X_{3}^{2}-51.17 X_{1} X_{2}+0.13 X_{1} X_{3}-0.50 X_{2} X_{3},
\end{aligned}
$$

$G_{(6)}$

$$
\begin{aligned}
= & -1.76+0.84 X_{1}+17.38 X_{2}+0.23 X_{3}+0.09 X_{1}^{2}+41.56 X_{2}^{2} \\
& -0.0 X_{3}^{2}-11.42 X_{1} X_{2}+0.04 X_{1} X_{3}-0.05 X_{2} X_{3} .
\end{aligned}
$$

The optimized values of factors were validated by repeating the experiment in triplicate flasks.

(2) Effect of Different Variables on DPPH Assay. Sucrose significantly affected the DPPH activity. The linear effect $\left(X_{1}\right)$ and the squared effect $\left(X_{1}^{2}\right)$ were significant $(P$ value $<.05)$, and the interactive effect $\left(X_{1} X_{2}\right)$ was highly significant $(P$ value $<.005)$. The response surface graphs showed the highest activity at $3-5 \%$ sucrose but with the least amount of $\mathrm{NaNO}_{3}$ while the activity decreased with the decrease in sucrose concentration and with the increase in the concentration of $\mathrm{NaNO}_{3}$ at a constant temperature of $25^{\circ} \mathrm{C}$. Maximum DPPH scavenging effect $(90 \%)$ was obtained at $5 \%$ sucrose, $0.05 \% \mathrm{NaNO}_{3}$, and at $35^{\circ} \mathrm{C}$ (Figure $1(\mathrm{a})$ ).

(3) Effect of Different Variables on Reducing Power. Linear effects $\left(X_{1}, X_{3}\right)$, squared effects $\left(X_{2}^{2}, X_{3}^{2}\right)$, and interactive effect between sucrose and temperature $\left(X_{1} X_{3}\right)$ was significant with $P$ value $<.5$. Interactive effect $\left(X_{1} X_{2}\right)$ was most significant at $P$ value $\leq .005$. The response surface graphs showed the highest reducing potential with an absorbance of 1.0 at $5 \%$ sucrose with $0.05 \%$ of $\mathrm{NaNO}_{3}$ and at a temperature of $35^{\circ} \mathrm{C}$ (Figure 1(b)).

(4) Effect of Different Variables on FRAP Assay, Ferrous Ion, and Nitric Oxide Ion Scavenging Activity. Effect of variables was similar on FRAP assay, ferrous ion, and nitric oxide ion scavenging activity. Interactive effect $\left(X_{1} X_{2}\right)$ was most significant with $P$ value $\leq .005$. While linear $\left(X_{2}\right)$, squared effect $\left(X_{1}^{2}, X_{2}^{2}\right)$ and interactive effect $\left(X_{1} X_{3}\right)$ showed significance at $P \leq .5$. At $35^{\circ} \mathrm{C}$, with medium composition of $5 \%$ sucrose and $0.05 \%$ of $\mathrm{NaNO}_{3}$, ferric reducing antioxidant power was highest (70\%) as compared to other medium conditions (Figure 1(c)). Similarly, the highest scavenging effect of $75 \%$ for nitric oxide ion was observed at $35^{\circ} \mathrm{C}$ with $5 \%$ and $0.05 \%$ of sucrose and $\mathrm{NaNO}_{3}$, respectively, (Figure $1(\mathrm{~d})$ ). The chelating effect $(70 \%)$ was highest at $35^{\circ} \mathrm{C}$ in the medium containing $5 \%$ sucrose with $0.05 \% \mathrm{NaNO}_{3}$. Antioxidant potential as assayed by different procedures demonstrated decrease in activity with increase of $\mathrm{NaNO}_{3}$ concentration and decrease in the temperature and sucrose concentration (Figure 1(e)).

(5) Effect of Different Variables on Total Phenolic Content. The interactive effect $\left(X_{1} X_{2}\right)$ was highly significant with $P$ value $\leq .005$ while linear $\left(X_{2}\right)$ and squared effect of sodium nitrate $\left(X_{2}^{2}\right)$, and interactive effect between sucrosetemperature $\left(X_{1} X_{3}\right)$ is significant with $P$ value $\leq .5$. The highest amount of TPC was obtained at 5\% sucrose and $0.05 \% \mathrm{NaNO}_{3}$ concentration at $35^{\circ} \mathrm{C}$ (Figure $1(\mathrm{f})$ ), and yield decreased with the decrease in temperature and sucrose concentration and with increase in $\mathrm{NaNO}_{3}$ concentration.

(6) Validation of Results. Thus from the overall assessment, $5 \%$ sucrose, $0.05 \% \mathrm{NaNO}_{3}$, and incubation temperature of $35^{\circ} \mathrm{C}$ and retaining other media components at standard concentration in Czapek Dox's medium may be regarded as the optimized conditions for different assay procedures. The $F$ value and $R^{2}$ value showed that the model correlated well with measured data and was statistically significant. To confirm the adequacy of the model for predicting maximum scavenging activity, the verification experiments using the optimum medium composition, as described above, were carried out in triplicates which showed $89.8 \%, 70.1 \%$, and $74.2 \%$ scavenging effect for DPPH radical, ferrous ion and nitric oxide ion, respectively. The yield for TPC was $12.3 \mathrm{mg} / \mathrm{mL}$ and reducing power showed 1.0 absorbance with $70.5 \%$ activity for FRAP assay. A good agreement between 


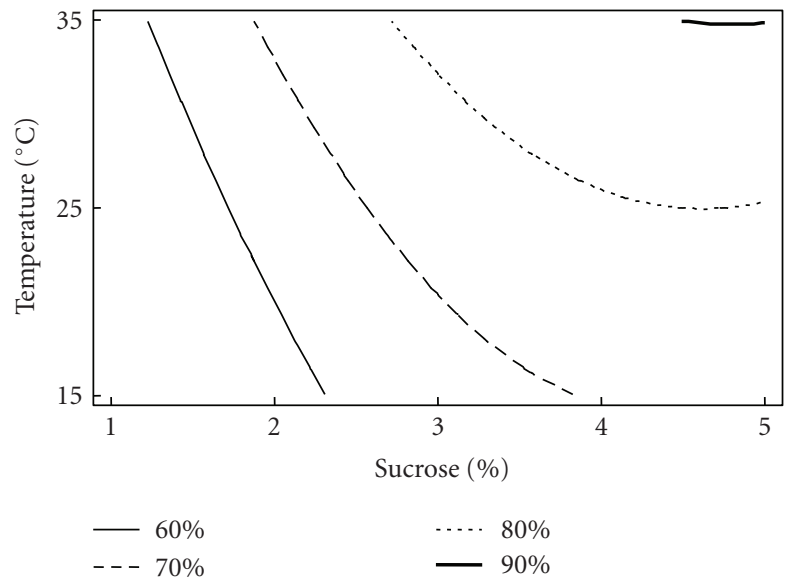

(a)

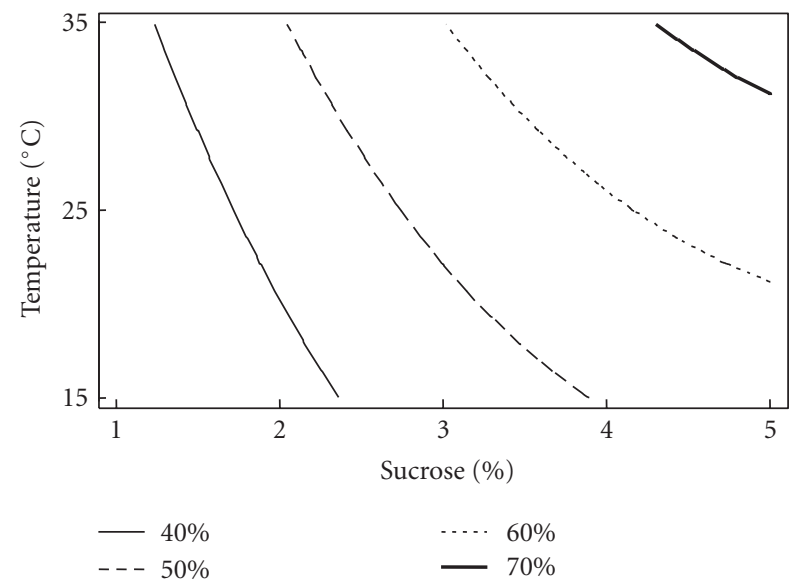

(c)

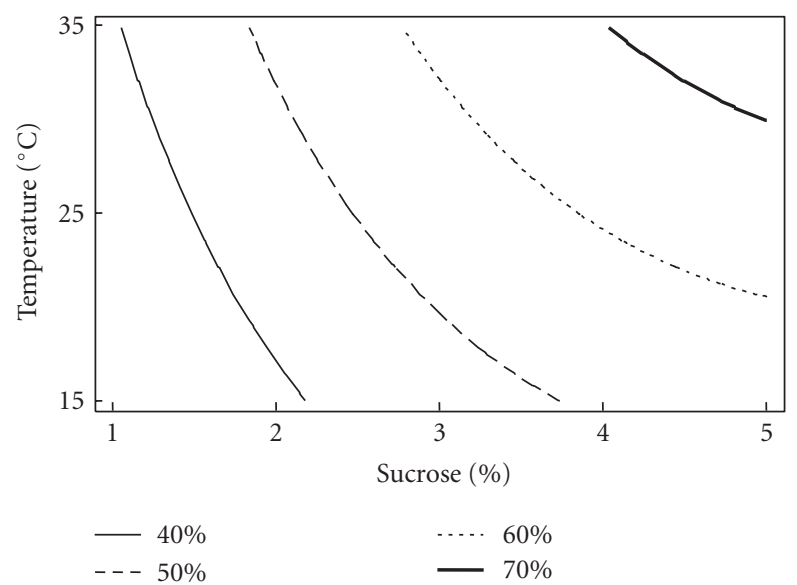

(e)

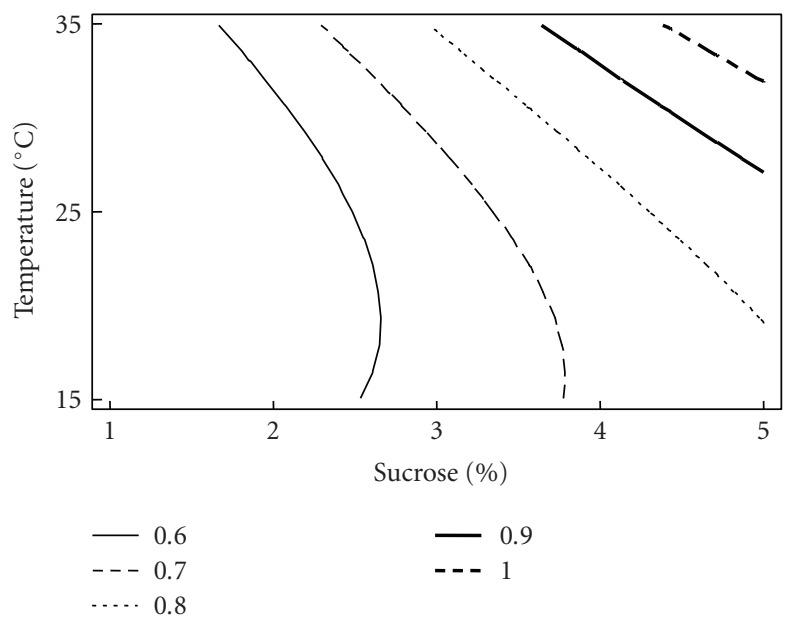

(b)

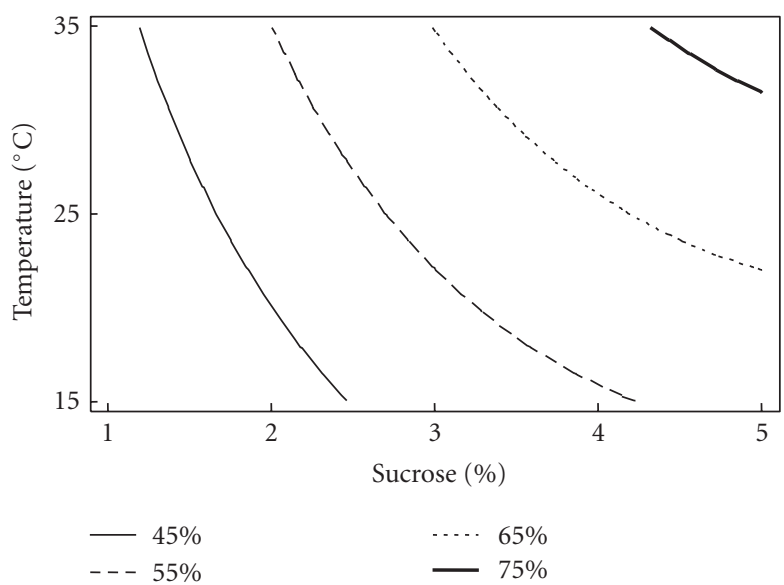

(d)

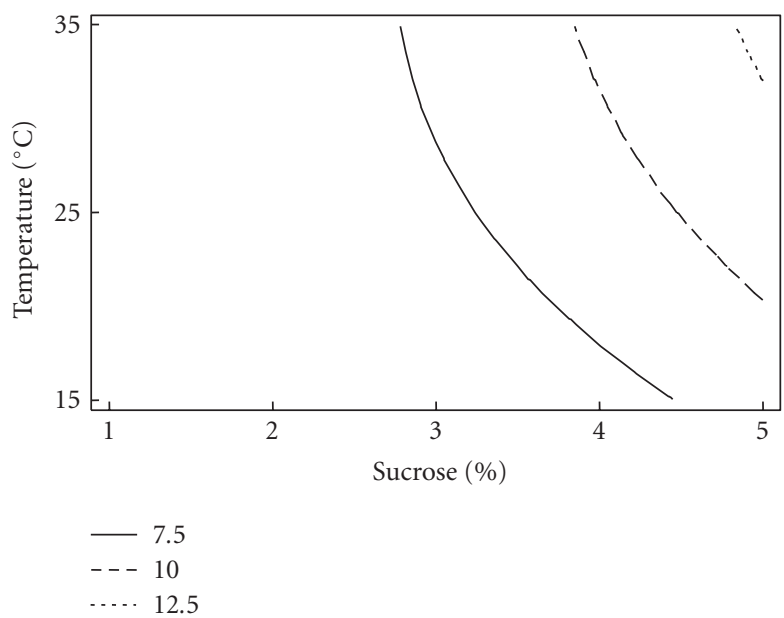

(f)

FIGURE 1: Contour graph showing effect of different variables on antioxidant potential (\% activity) as assayed by different procedures (a) 1,1-diphenyl-2-picryl hydrazyl free radical (DPPH) assay (hold value: $0.05 \%$ of sodium nitrate); (b) reducing power (in absorbance) (hold value: $0.05 \%$ of sodium nitrate); (c) ferrous ion scavenging activity (hold value: $0.05 \%$ of sodium nitrate); (d) nitric oxide ion scavenging activity (hold value: $0.05 \%$ of sodium nitrate); (e) FRAP assay (hold value: $0.05 \%$ of sodium nitrate); (f) total phenolic content (mg/mL) (hold value: $0.05 \%$ of sodium nitrate). 
TABLE 1: Effect of various carbon sources on antioxidant potential of Aspergillus fumigatus.

\begin{tabular}{|c|c|c|c|c|c|c|}
\hline$\%$ activity & Dextrose & Maltose & Lactose & Starch & Glycerol & Sucrose \\
\hline $\mathrm{DPPH}^{*}$ assay & $62.2 \pm 0.06$ & $60.8 \pm 0.5$ & $50.6 \pm 0.4$ & $56.7 \pm 0.4$ & $32.9 \pm 0.2$ & $68.96 \pm 0.47$ \\
\hline Reducing power & $0.42 \pm 0.03$ & $0.40 \pm 0.02$ & $0.3 \pm 0.02$ & $0.4 \pm 0.7$ & $0.16 \pm 0.4$ & $0.510 \pm 00$ \\
\hline $\mathrm{Fe}^{2+}$ scavenging activity & $45.3 \pm 0.9$ & $42.1 \pm 0.08$ & $35.3 \pm 0.1$ & $40.3 \pm 0.55$ & $24.3 \pm 0.5$ & $48.3 \pm 0.3$ \\
\hline $\mathrm{FRAP}^{* *}$ assay & $40.7 \pm 0.2$ & $38.8 \pm 0.09$ & $32.9 \pm 0.2$ & $35.4 \pm 0.3$ & $25.6 \pm 0.5$ & $45.2 \pm 0.2$ \\
\hline \multicolumn{7}{|l|}{$\mathrm{NO}^{* * *}$ scavenging activity } \\
\hline $30 \mathrm{~min}$ & $24.6 \pm 0.2$ & $23.8 \pm 0.1$ & $12.5 \pm 0.4$ & $16.7 \pm 0.01$ & $10.3 \pm 0.2$ & $28.2 \pm 0.7$ \\
\hline $60 \mathrm{~min}$ & $30.2 \pm 0.3$ & $30.5 \pm 0.4$ & $18.4 \pm 0.02$ & $22.6 \pm 0.3$ & $18.4 \pm 0.5$ & $35.2 \pm 0.02$ \\
\hline $90 \mathrm{~min}$ & $38.3 \pm 0.1$ & $34.2 \pm 0.6$ & $21.8 \pm 0.2$ & $26.8 \pm 0.02$ & $20.4 \pm 0.8$ & $40.2 \pm 0.8$ \\
\hline $120 \mathrm{~min}$ & $40.3 \pm 0.1$ & $38.6 \pm 0.1$ & $26.3 \pm 0.2$ & $30.2 \pm 0.4$ & $25.5 \pm 0.3$ & $45.3 \pm 0.11$ \\
\hline $180 \mathrm{~min}$ & $45.3 \pm 0.02$ & $40.8 \pm 0.02$ & $30.8 \pm 0.5$ & $35.2 \pm 0.88$ & $28.9 \pm 0.32$ & $50.2 \pm 0.45$ \\
\hline $\mathrm{TPC}^{* * * *}(\mathrm{mg} / \mathrm{mL})$ & $4.2 \pm 0.1$ & $3.8 \pm 0.5$ & $2.1 \pm 0.07$ & $3.2 \pm 0.4$ & $1.0 \pm 0.7$ & $5.68 \pm 0.03$ \\
\hline Biomass (mg) & $35.4 \pm 0.2$ & $30.4 \pm 0.04$ & $20.6 \pm 0.06$ & $26.7 \pm 0.3$ & $12.6 \pm 0.02$ & $40.8 \pm 0.3$ \\
\hline
\end{tabular}

${ }^{*} \mathrm{DPPH}$ : 1.1-diphenyl-2-picryl hydrazyl; **FRAP: ferric reducing antioxidant power; $* * * \mathrm{NO}$ : nitric oxide; $* * *$ TPC: total phenolic content; values are means of three replicates \pm S.D.

TABLE 2: Effect of various nitrogen sources on antioxidant potential of Aspergillus fumigatus.

\begin{tabular}{|c|c|c|c|c|c|c|c|}
\hline \multicolumn{8}{|c|}{ Antioxidant activity (\%) } \\
\hline Nitrogen sources & $\mathrm{DPPH}^{*}$ assay & $\begin{array}{l}\text { Reducing } \\
\text { power }\end{array}$ & $\begin{array}{c}\mathrm{Fe}^{2+} \text { scavenging } \\
\text { activity }\end{array}$ & $\begin{array}{c}\operatorname{FRAP}^{* *} \\
\text { assay }\end{array}$ & $\begin{array}{c}\mathrm{NO}^{* * *} \text { scavenging } \\
\text { activity }\end{array}$ & $\begin{array}{l}\text { TPC**** } \\
(\mathrm{mg} / \mathrm{mL})\end{array}$ & $\begin{array}{l}\text { Biomass } \\
(\mathrm{mg})\end{array}$ \\
\hline \multicolumn{8}{|c|}{$\begin{array}{l}\text { Nitrogen rich organic } \\
\text { supplements }\end{array}$} \\
\hline Yeast extract & $65.8 \pm 0.6$ & $0.48 \pm 0.7$ & $42.7 \pm 0.1$ & $40.2 \pm 0.3$ & $30.7 \pm 0.04$ & $34.8 \pm 0.3$ & $38.8 \pm 0.04$ \\
\hline Peptone & $65.8 \pm 0.5$ & $0.463 \pm 0.6$ & $42.3 \pm 0.2$ & $40.1 \pm 0.2$ & $30.1 \pm 0.6$ & $35.2 \pm 0.2$ & $37.6 \pm 0.06$ \\
\hline Malt extract & $58.3 \pm 0.5$ & $0.35 \pm 0.3$ & $37.8 \pm 0.5$ & $35.6 \pm 0.01$ & $25.7 \pm 0.2$ & $30.5 \pm 0.3$ & $35.8 \pm 0.5$ \\
\hline Casein & $60.3 \pm 0.07$ & $0.40 \pm 0.07$ & $40.5 \pm 0.4$ & $37.7 \pm 0.6$ & $22.8 \pm 0.4$ & $31.9 \pm 0.5$ & $35.7 \pm 0.2$ \\
\hline Soyabean meal & $52.3 \pm 0.5$ & $0.22 \pm 0.02$ & $35.2 \pm 0.5$ & $32.7 \pm 0.02$ & $20.7 \pm 0.02$ & $25.4 \pm 0.1$ & $28.7 \pm 0.5$ \\
\hline Urea & $20.4 \pm 0.1$ & - & - & - & - & - & $8.6 \pm 0.04$ \\
\hline \multicolumn{8}{|l|}{$\begin{array}{l}\text { Inorganic nitrogen } \\
\text { sources }\end{array}$} \\
\hline $\mathrm{KNO}_{3}$ & $45.2 \pm 0.05$ & $0.302 \pm 0.01$ & $28.5 \pm 0.6$ & $25.7 \pm 0.03$ & $15.8 \pm 0.05$ & $17.8 \pm 0.04$ & $20.6 \pm 0.78$ \\
\hline$\left(\mathrm{NH}_{4}\right)_{2} \mathrm{SO}_{4}$ & $46.7 \pm 0.03$ & $0.320 \pm 0.5$ & $28.9 \pm 0.5$ & $26.7 \pm 0.5$ & $15.3 \pm 0.1$ & $28.9 \pm 0.1$ & $20.7 \pm 0.6$ \\
\hline$\left(\mathrm{NH}_{4}\right) \mathrm{HSO}_{4}$ & $40.3 \pm 0.06$ & $0.206 \pm 0.1$ & $25.3 \pm 0.03$ & $22.8 \pm 0.7$ & $10.3 \pm 0.2$ & $18.9 \pm 0.1$ & $20.8 \pm 0.3$ \\
\hline $\mathrm{NH}_{4} \mathrm{NO}_{3}$ & $36.2 \pm 0.01$ & $0.18 \pm 0.03$ & $24.5 \pm 0.1$ & $21.9 \pm 0.8$ & $10.8 \pm 0.5$ & $12.8 \pm 0.2$ & $18.6 \pm 0.4$ \\
\hline $\mathrm{NaNO}_{3}$ & $68.9 \pm 0.4$ & $0.510 \pm 00$ & $48.3 \pm 0.3$ & $45.2 \pm 0.22$ & $28.2 \pm 0.7$ & $35.2 \pm 0.02$ & $40.2 \pm 0.8$ \\
\hline $\mathrm{NH}_{4} \mathrm{Cl}$ & $50.3 \pm 0.7$ & $0.26 \pm 0.5$ & $30.2 \pm 0.1$ & $28.6 \pm 0.3$ & $16.9 \pm 0.2$ & $20.6 \pm 0.3$ & $25.7 \pm 0.1$ \\
\hline
\end{tabular}

${ }^{*}$ DPPH: 1.1-diphenyl: 2-picryl hydrazyl; **FRAP: ferric reducing antioxidant power; ${ }^{* * *}$ NO: nitric oxide; ${ }^{* * *}$ TPC: total phenolic content; values are means of three replicates \pm S.D.

the predicted and experimental results verified the validity of the model and the improvement of antioxidant activity indicated that RSM is a powerful tool for determining the exact optimal values of the individual factors and the maximum response value.

3.5. Thermostability of Antioxidant Activity. The culture filtrate of Aspergillus fumigatus showing antioxidant activity was found to be relatively thermostable as it suffered a slight loss in its activity with increase in temperature. At $40^{\circ} \mathrm{C}$, the activity decreased by only $7 \%$ in fungal extracts, while at $100^{\circ} \mathrm{C}$ it suffered a maximum loss of $50 \%$ in its activity.
3.6. Extraction of Bioactive Compound in Different Organic Solvents. The extraction of culture broth with different organic solvents revealed ethyl acetate to be the best to elute the components responsible for antioxidant potential and it was followed by chloroform and butanol. Petroleum ether extracts did not show any activity. The ethyl acetate extract showed $74.6 \%, 68.8 \%$, and $70.5 \%$ scavenging activity for $\mathrm{DPPH}$, ferrous, and NO ion, respectively. Ferric reducing antioxidant power and reducing potential was $65.6 \%$ and 1.1. The chloroform extract showed 0.78 reducing potential with ferric ion reduction of $55.3 \%$ and $67.4 \%, 56.7 \%$, and $56.9 \%$ of scavenging effect for DPPH, ferrous, and NO ion, respectively. Butanol extract exhibited reducing potential of 
TABle 3: Plackett-Burman design variables with antioxidant potential of Aspergillus fumigates.

\begin{tabular}{|c|c|c|c|c|c|c|c|c|c|c|c|}
\hline \multirow[b]{2}{*}{ Run } & \multicolumn{5}{|c|}{ Variables (\%) } & \multicolumn{6}{|c|}{ Antioxidant activity (\%) } \\
\hline & Sucrose & $\mathrm{NaNO}_{3}$ & $\mathrm{~K}_{2} \mathrm{HPO}_{4}$ & $\mathrm{MgSO}_{4}$ & $\mathrm{KCl}$ & $\begin{array}{c}\mathrm{DPPH}^{*} \\
\text { assay }\end{array}$ & $\begin{array}{c}\text { Reducing } \\
\text { power }\end{array}$ & $\begin{array}{c}\mathrm{Fe}^{2+} \text { scavenging } \\
\text { activity }\end{array}$ & $\begin{array}{c}\mathrm{FRAP}^{* *} \\
\text { assay }\end{array}$ & $\begin{array}{c}\mathrm{NO}^{* * *} \\
\text { scavenging } \\
\text { activity }\end{array}$ & $\begin{array}{l}\mathrm{TPC}^{* * * *} \\
(\mathrm{mg} / \mathrm{mL})\end{array}$ \\
\hline 1 & 5.0 & 0.000 & 0.18 & 0.000 & 0.000 & 58.1 & 0.48 & 44.3 & 45.7 & 48.30 & 4.80 \\
\hline 2 & 5.0 & 0.350 & 0.00 & 0.090 & 0.000 & 65.4 & 0.72 & 48.1 & 50.3 & 52.30 & 5.80 \\
\hline 3 & 0.0 & 0.350 & 0.18 & 0.000 & 0.090 & 25.3 & 0.20 & 20.3 & 25.6 & 28.20 & 1.80 \\
\hline 4 & 5.0 & 0.000 & 0.18 & 0.090 & 0.000 & 50.3 & 0.40 & 40.9 & 42.1 & 45.30 & 4.80 \\
\hline 5 & 5.0 & 0.350 & 0.00 & 0.090 & 0.090 & 72.1 & 0.63 & 54.2 & 56.3 & 60.20 & 6.20 \\
\hline 6 & 5.0 & 0.350 & 0.18 & 0.000 & 0.090 & 65.4 & 0.55 & 48.3 & 50.6 & 55.60 & 5.30 \\
\hline 7 & 0.0 & 0.350 & 0.18 & 0.090 & 0.000 & 23.4 & 0.19 & 18.6 & 20.3 & 25.40 & 1.40 \\
\hline 8 & 0.0 & 0.000 & 0.18 & 0.090 & 0.090 & 48.2 & 0.36 & 37.3 & 40.1 & 45.20 & 4.00 \\
\hline 9 & 0.0 & 0.000 & 0.00 & 0.090 & 0.090 & 20.8 & 0.11 & 15.2 & 17.2 & 20.20 & 1.01 \\
\hline 10 & 5.0 & 0.000 & 0.00 & 0.000 & 0.090 & 60.3 & 0.50 & 46.2 & 45.3 & 48.30 & 5.00 \\
\hline 11 & 0.0 & 0.350 & 0.00 & 0.000 & 0.000 & 54.3 & 0.45 & 42.1 & 40.2 & 45.03 & 4.50 \\
\hline 12 & 0.0 & 0.000 & 0.00 & 0.000 & 0.000 & 0.0 & 0.00 & 0.0 & 0.0 & 0.00 & 0.00 \\
\hline 13 & 2.5 & 0.175 & 0.09 & 0.045 & 0.045 & 69.2 & 0.58 & 49.0 & 47.2 & 52.20 & 6.00 \\
\hline 14 & 2.5 & 0.175 & 0.09 & 0.045 & 0.045 & 68.4 & 0.57 & 48.2 & 47.1 & 52.10 & 6.10 \\
\hline
\end{tabular}

${ }^{*}$ DPPH: 1.1-diphenyl -2-picryl hydrazyl; **FRAP: Ferric reducing antioxidant power; ${ }^{* * *}$ NO: nitric oxide; $* * * *$ TPC: total phenolic content.

TABLE 4: Box-Behnken designs of different variables with antioxidant potential of Aspergillus fumigates.

\begin{tabular}{|c|c|c|c|c|c|c|c|c|c|}
\hline \multicolumn{4}{|c|}{ Variables (\%) } & \multicolumn{6}{|c|}{ Antioxidant activity (\%) } \\
\hline Run & Sucrose & $\mathrm{NaNO}_{3}$ & Temperature & DPPH Assay & $\begin{array}{c}\text { Reducing } \\
\text { power }\end{array}$ & $\begin{array}{c}\mathrm{Fe}^{2+} \text { scavenging } \\
\text { activity }\end{array}$ & FRAP assay & $\begin{array}{c}\text { NO scavenging } \\
\text { activity }\end{array}$ & $\begin{array}{c}\text { TPC } \\
(\mathrm{mg} / \mathrm{mL})\end{array}$ \\
\hline 1 & 1 & 0.05 & 25 & 52.3 & 0.42 & 38.4 & 35.3 & 41.8 & 4.6 \\
\hline 2 & 5 & 0.05 & 25 & 77.8 & 0.81 & 62.3 & 60.2 & 65.2 & 10.3 \\
\hline 3 & 1 & 0.35 & 25 & 78.1 & 0.83 & 64.4 & 65.4 & 68.1 & 10.9 \\
\hline 4 & 5 & 0.35 & 25 & 42.3 & 0.42 & 28.1 & 25.3 & 30.1 & 2.9 \\
\hline 5 & 1 & 0.20 & 15 & 45.4 & 0.48 & 30.4 & 28.2 & 32.4 & 3.1 \\
\hline 6 & 5 & 0.20 & 15 & 47.8 & 0.48 & 32.3 & 30.3 & 35.2 & 3.8 \\
\hline 7 & 1 & 0.20 & 35 & 69.2 & 0.63 & 50.1 & 48.3 & 52.4 & 6.1 \\
\hline 8 & 5 & 0.20 & 35 & 78.0 & 0.89 & 62.4 & 60.1 & 65.3 & 10.2 \\
\hline 9 & 3 & 0.05 & 15 & 70.5 & 0.71 & 50.2 & 50.2 & 53.2 & 6.2 \\
\hline 10 & 3 & 0.35 & 15 & 69.3 & 0.62 & 50.8 & 49.2 & 53.3 & 6.0 \\
\hline 11 & 3 & 0.05 & 35 & 76.4 & 0.78 & 56.2 & 54.3 & 59.3 & 6.9 \\
\hline 12 & 3 & 0.35 & 35 & 74.2 & 0.72 & 54.3 & 51.2 & 56.4 & 6.4 \\
\hline 13 & 3 & 0.20 & 25 & 69.0 & 0.59 & 50.1 & 45.3 & 52.6 & 5.8 \\
\hline 14 & 3 & 0.20 & 25 & 68.8 & 0.61 & 50.2 & 46.3 & 52.1 & 5.8 \\
\hline 15 & 3 & 0.20 & 25 & 69.3 & 0.58 & 48.3 & 46.2 & 50.1 & 6.1 \\
\hline 16 & 3 & 0.20 & 25 & 69.8 & 0.62 & 48.2 & 47.2 & 52.4 & 6.0 \\
\hline 17 & 3 & 0.20 & 25 & 68.9 & 0.51 & 48.3 & 45.2 & 50.2 & 5.7 \\
\hline
\end{tabular}

0.34 and $38.7 \%$ of ferric reducing antioxidant power with scavenging effect of $50 \%, 35.5 \%$, and $40.8 \%$ for $\mathrm{DPPH}$, ferrous and NO ion, respectively.

3.7. Toxicity Tests. The cell-free fungal extracts, when studied for Ames test, showed no mutagenic activity as no bacterial colony was observed on agar plates containing fungal extracts, while more than 1000 colonies were observed on positive control (sodium azide) containing plate. Similarly, results obtained from MTT assay revealed that the cellfree extracts were noncytotoxic and showed much higher absorbance (0.775) as compared to positive control (0.107).

\section{Discussion}

A number of fungi, in particular mushrooms, have been known to possess good antioxidant activity [16]. However, much work still needs to be done to explore filamentous 
fungi for antioxidant activity, and the results shown by Aspergillus fumigatus support this contention [17]. Antioxidant activity, as assayed by different methods, demonstrated static culture of Aspergillus fumigatus to be more suitable as compared to shake flask culture. This supports the earlier observation of various researchers who have used static conditions [18] or low RPM (between 100 to 150 RPM) $[17,19,20]$. It might be attributed to a low amount of phenolic compounds produced under shaking conditions, which have been held responsible for antioxidant activity of fungi. Ten days of incubation period was optimum for antioxidant activity, and the subsequent decline in bioactivity could be due to the exhaustion of nutrients available for the fungi. This decline may also be attributed to the degradation of secondary metabolites (phenolic compounds) already produced by fungi as supported by decline in the phenolic content.

The comparison of antioxidant activity of the cell-free culture broth obtained from the fungus grown at different temperatures revealed $25^{\circ} \mathrm{C}$ to be the optimum temperature, which correlate positively with its phenolic content. No activity was detected at $\mathrm{pH}$ extremes, which was optimally best between the $\mathrm{pH} 5$ and 7 . The present results corroborate the previous studies done by Miao et al. [21] on antibacterial activity from fungal sources in which there was no bioactivity at $\mathrm{pH}$ extremes. This may be due to delayed metabolite production caused by delayed mycelial growth or due to reduced production of bioactive metabolites under such $\mathrm{pH}$ conditions. This shows that $\mathrm{pH}$ of the growth medium can also significantly affect the production of secondary metabolites. The $\mathrm{pH}$ is related to permeability characteristics of the cell wall and membrane, thus affecting either ion uptake or loss to the nutrient medium [22].

Sucrose and sodium nitrate were found to be the most promising carbon and nitrogen sources for obtaining the best antioxidant activity by Aspergillus fumigatus which is in consonance with earlier studies carried out on Aspergillus candidus [23]. However, it contravenes the general perception that glucose and starch are the best carbon source for fungal growth. The results thus suggest that a fungal species may have the ability to utilize a particular carbon source for vegetative growth but may not be able to use it for production of specialized metabolites. This signifies that availability of easily utilizable carbon and nitrogen sources (sucrose and $\mathrm{NaNO}_{3}$ ) may lead to the formation of secondary metabolites. All carbon and nitrogen sources are divided into quickly metabolizable sources and sustainable sources. Quickly metabolizable sources are beneficial for faster growth of microorganisms and relieving their need for long-term accumulation of products. Sucrose and $\mathrm{NaNO}_{3}$ are regarded as sustainable sources, which favors the production of secondary metabolites as these are the products of later growth [24]. The study thus demonstrated the basic composition of Czapek Dox's medium to be the best for effective production of antioxidant activity. In fact, culture media designing has a major impact on the growth of microbes and the production of microbial products [21].

Further analysis of the effect of the medium constituents through Plackett Burman design showed sucrose and $\mathrm{NaNO}_{3}$ to be significant but the significance of $\mathrm{NaNO}_{3}$ was less than $50 \%$. The results got further support from the RSM observations where low concentration of $\mathrm{NaNO}_{3}$ in the medium favors the antioxidant activity. This demonstrates importance of nitrogen sources in regulating the production of secondary metabolites [25]. Sucrose is beneficial for the growth of fungi as well as for production of secondary metabolites which are responsible for their antioxidant activity.

Though $\mathrm{KCl}, \mathrm{MgSO}_{4}$, and $\mathrm{K}_{2} \mathrm{HPO}_{4}$ did not significantly affect the antioxidant activity, still they are retained are retained at standard concentration in Czapek Dox's medium because magnesium and potassium are required by all the fungi for a variety of regulatory functions and control the biosynthesis of various secondary metabolites. This shows that the medium most suitable for growth may or may not be equally effective for secondary metabolites and thus enhancement of secondary metabolites can only be achieved through systematic manipulation of different parameters [26].

Thermostability studies on cell-free extract demonstrated that metabolites responsible for antioxidant activity are quite stable at $40^{\circ} \mathrm{C}$. Of the different organic solvents tried for extraction, ethyl acetate showed the best activity followed by chloroform and butanol extract. Our observations with ethyl acetate extracts are in consonance with earlier studies $[23,27]$. Further, the results of ethyl acetate extracts were quite comparable with the activity of ascorbic acid (96.7\%), BHA (95.1\%), and alpha tocopherol (94.7\%).

It is commonly known that the antioxidative effects are mainly due to redox properties of phenolic compounds which can play an important role in absorbing and neutralizing the free radicals by acting as reducing agents and hydrogen donor, quenching singlet and triplet oxygen or decomposing peroxides [19]. The importance of phenolic contents has been endorsed by their high content in Aspergillus fumigatus and their antioxidant activity is quite comparable to that of many mushrooms as well as medicinal plants. Further, the better production of phenolics under optimized conditions also enhanced the antioxidant activity.

The results obtained indicate Aspergillus fumigatus to be a potent antioxidant producer having broad spectrum against various free radicals. Previous studies have shown the linear correlation between total phenolic content and antioxidant activity; total phenolic content of Aspergillus fumigatus correlated well with the antioxidant activity which is in consonance with earlier studies [28]. The extract obtained from Aspergillus fumigatus showed good activity against DPPH radical by neutralizing the free radical character of purple color DPPH, either by transfer of electron or hydrogen atom to yellow-colored diamagnetic molecule revealing hydrogen donating property of phenolic compounds present in the extract which can be supported by the positive correlation $(r=0.817)$ between the results of DPPH assay and TPC [29]. Similarly, positive correlation $(r=0.815)$ was found between reducing power assay and TPC. Reducing power assay proves the potential of the phenolic compounds in the extracts to act as reductones that inhibit lipid peroxidation by donating a hydrogen atom thereby terminating the free radical chain reaction. Moreover, this reducing potential may be due to 
the di- or monohydroxy substitution in the aromatic rings that possess potent hydrogen donating ability [9]. Results of FRAP assay are also positively correlated $(r=0.856)$ with TPC and good activity of the fungal extract for FRAP assay denotes its reducing potential. Generally, the reducing properties are associated to the breaking of free radical chain by donating a hydrogen atom [11]. The extracts also showed appreciable chelating activity of metals, as the transition metals such as ferrous ion can stimulate lipid peroxidation by generating hydroxyl radicals through Fenton reaction. The chelating activity for ferrous ion was assayed by the inhibition of formation of red-colored ferrozine and ferrous complex. There was positive-correlation $(r=0.819)$ between chelating activity and TPC [9]. As evident from studies, the cell-free extracts are able to scavenge nitric oxide ion, and correlation with TPC was found to be positive $(r=0.813)$.

Most of the literature is available on antioxidant activity of plants and mushrooms, though some of the fungi are known to produce antioxidant activity. To the best of our knowledge, apparently this is the first systematic report on antioxidant activity of Aspergillus fumigatus demonstrated by different assay procedures and its optimization by statistical methods. Under optimal condition, Aspergillus fumigatus showed $89.8 \%, 70.1 \%$, and $74.2 \%$ scavenging effect for DPPH radical, ferrous ion and nitric oxide ion, respectively. The yield for TPC was $12.3 \mathrm{mg} / \mathrm{mL}$ and reducing power showed absorbance of 1.0 and $70.5 \%$ activity for FRAP assay. The results showed the scavenging effect for DPPH radical, ferrous ion, and nitric oxide ion was enhanced by 1.3, 1.4 , and 1.4 folds, respectively, while reducing potential and ferric reduction rate was enhanced by 2.0 and 1.3 folds. The production of TPC was enhanced by 2.1 folds. These results are also comparable with the antioxidant activity of various other fungi, Aspergillus candidus, Chaetomium sp., Cladosporium sp, Colletotrichum gloeosporioides [30] and many mushrooms such as Lentinus edodes, Volvariella volvacea [16] and many medicinal plants like Amaranthus paniculatus, Aerva lanata, Coccinia indica, Coriandrum sativum [31]. To further highlight the importance of the study, the results of the cell-free extract also exhibited higher activity than synthetic antioxidants (BHA and BHT).

\section{Conclusions}

Hence, the above study suggests that not only mushrooms and plants but some other fungi may also be a good source of antioxidant compounds and Aspergillus fumigatus is one such potential candidate offering a better scope for production and easier downstreaming of such bioactive compounds as toxicity studies proved that extract is neither cytotoxic nor mutagenic. These findings will facilitate the further studies to gain better understanding of production of bioactive metabolites in fungi, which will be helpful in their biotechnological mass production in the near future.

\section{Acknowledgement}

P. Chandra is thankful to UGC for Rajiv Gandhi National Fellowship no. F.42 (SC)/2008 (SA-III).

\section{References}

[1] I. H. Lee, Y. H. Hung, and C. C. Chou, "Solid-state fermentation with fungi to enhance the antioxidative activity, total phenolic and anthocyanin contents of black bean," International Journal of Food Microbiology, vol. 121, no. 2, pp. 150-156, 2008.

[2] N. Radulović, V. Stankov-Jovanović, G. Stojanović, A. Šmelcerović, M. Spiteller, and Y. Asakawa, "Screening of in vitro antimicrobial and antioxidant activity of nine Hypericum species from the Balkans," Food Chemistry, vol. 103, no. 1, pp. 15-21, 2007.

[3] T. Bhanja, A. Kumari, and R. Banerjee, "Enrichment of phenolics and free radical scavenging property of wheat koji prepared with two filamentous fungi," Bioresource Technology, vol. 100, no. 11, pp. 2861-2866, 2009.

[4] S. Surveswaran, Y. Z. Cai, H. Corke, and M. Sun, "Systematic evaluation of natural phenolic antioxidants from 133 Indian medicinal plants," Food Chemistry, vol. 102, no. 3, pp. 938953, 2007.

[5] K. F. Rodrigues, G. L. Costa, M. P. Carvalho, and R. D. A. Epifanio, "Evaluation of extracts produced by some tropical fungi as potential cholinesterase inhibitors," World Journal of Microbiology and Biotechnology, vol. 21, no. 8-9, pp. 16171621, 2005.

[6] D. S. Arora and P. Chandra, "Chandra Antioxidant activity of fungi isolated from soil," Brazilian Journal of Microbiology, vol. 41, pp. 465-477, 2010.

[7] D. B. Archer, "Filamentous fungi as microbial cell factories for food use," Current Opinion in Biotechnology, vol. 11, no. 5, pp. 478-483, 2000.

[8] P. Chandra and D. S. Arora, "Antioxidant activity of fungi isolated from soil of different areas of Punjab," Indian Journal of Applied and Natural Science, vol. 1, pp. 123-128, 2009.

[9] G. R. Zhao, Z. J. Xiang, T. X. Ye, Y. J. Yuan, and Z. X. Guo, "Antioxidant activities of Salvia miltiorrhiza and Panax notoginseng," Food Chemistry, vol. 99, no. 4, pp. 767-774, 2006.

[10] L. W. Chang, W. J. Yen, S. C. Huang, and P. D. Duh, "Antioxidant activity of sesame coat," Food Chemistry, vol. 78, no. 3, pp. 347-354, 2002.

[11] A. Othman, A. Ismail, N. Abdul Ghani, and I. Adenan, "Antioxidant capacity and phenolic content of cocoa beans," Food Chemistry, vol. 100, no. 4, pp. 1523-1530, 2007.

[12] K. S. Kang, T. Yokozawa, H. Y. Kim, and J. H. Park, "Study on the nitric oxide scavenging effects of ginseng and its compounds," Journal of Agricultural and Food Chemistry, vol. 54, no. 7, pp. 2558-2562, 2006.

[13] V. L. Singleton, R. Ortofehr, and R. M. Lamuela-Raventos, "Analysis of total phenols and other oxidation substrate and antioxidants by means of Folin-Ciocalteau reagent," Methods in Enzymology, vol. 299, pp. 152-178, 1999.

[14] D. M. Maron and B. N. Ames, "Revised methods for the Salmonella mutagenicity test," Mutation Research, vol. 113, no. 3-4, pp. 173-215, 1983.

[15] G. Ciapetti, E. Cenni, L. Pratelli, and A. Pizzoferrato, "In vitro evaluation of cell/biomaterial interaction by MTT assay," Biomaterials, vol. 14, no. 5, pp. 359-364, 1993.

[16] L. M. Cheung and P. C. K. Cheung, "Mushroom extracts with antioxidant activity against lipid peroxidation," Food Chemistry, vol. 89, no. 3, pp. 403-409, 2005.

[17] G. C. Yen and C. A. Lee, "Antioxidant activity of extracts from molds," Journal of Food Protection, vol. 59, no. 12, pp. 13271330, 1996. 
[18] J. K. Harper, A. M. Arif, E. J. Ford et al., "Pestacin: a 1,3dihydro isobenzofuran from Pestalotiopsis microspora possessing antioxidant and antimycotic activities," Tetrahedron, vol. 59, no. 14, pp. 2471-2476, 2003.

[19] W. Y. Huang, Y. Z. Cai, K. D. Hyde, H. Corke, and M. Sun, "Endophytic fungi from Nerium oleander L (Apocynaceae): main constituents and antioxidant activity," World Journal of Microbiology and Biotechnology, vol. 23, no. 9, pp. 1253-1263, 2007.

[20] P. P. Malpure, A. S. Shah, and A. R. Juvekar, "Antioxidant and anti-inflammatory activity of extract obtained from Aspergillus candidus MTCC 2202 broth filtrate," Indian Journal of Experimental Biology, vol. 44, no. 6, pp. 468-473, 2006.

[21] L. I. Miao, T. F. N. Kwong, and P. Y. Qian, "Effect of culture conditions on mycelial growth, antibacterial activity, and metabolite profiles of the marine-derived fungus Arthrinium c.f. saccharicola," Applied Microbiology and Biotechnology, vol. 72, no. 5, pp. 1063-1073, 2006.

[22] T. Yamanaka, "The effect of $\mathrm{pH}$ on the growth of saprotrophic and ectomycorrhizal ammonia fungi in vitro," Mycologia, vol. 95, no. 4, pp. 584-589, 2003.

[23] G. C. Yen and Y. C. Chang, "Medium optimization for the production of antioxidants from Aspergillus candidus," Journal of Food Protection, vol. 62, no. 6, pp. 657-661, 1999.

[24] A. Daza, J. L. Manjón, M. Camacho, L. Romero De La Osa, A. Aguilar, and C. Santamaría, "Effect of carbon and nitrogen sources, $\mathrm{pH}$ and temperature on in vitro culture of several isolates of Amanita caesarea (Scop.:Fr.) Pers," Mycorrhiza, vol. 16, no. 2, pp. 133-136, 2006.

[25] D. K. Gogoi, H. P. Deka Boruah, R. Saikia, and T. C. Bora, "Optimization of process parameters for improved production of bioactive metabolite by a novel endophytic fungus Fusarium sp. DF2 isolated from Taxus wallichiana of North East India," World Journal of Microbiology and Biotechnology, vol. 24, no. 1, pp. 79-87, 2008.

[26] S. Trupkin, L. Levin, F. Forchiassin, and A. Viale, "Optimization of a culture medium for ligninolytic enzyme production and synthetic dye decolorization using response surface methodology," Journal of Industrial Microbiology and Biotechnology, vol. 30, no. 12, pp. 682-690, 2003.

[27] G. C. Yen, Y. C. Chang, F. Sheu, and H. C. Chiang, "Isolation and characterization of antioxidant compounds from Aspergillus candidus broth filtrate," Journal of Agricultural and Food Chemistry, vol. 49, no. 3, pp. 1426-1431, 2001.

[28] B. Sultana, F. Anwar, and R. Przybylski, "Antioxidant activity of phenolic components present in barks of Azadirachta indica, Terminalia arjuna, Acacia nilotica, and Eugenia jambolana Lam. trees," Food Chemistry, vol. 104, no. 3, pp. 11061114, 2007.

[29] S. Bounatirou, S. Smiti, M. G. Miguel et al., "Chemical composition, antioxidant and antibacterial activities of the essential oils isolated from Tunisian Thymus capitatus Hoff. et link," Food Chemistry, vol. 105, pp. 146-155, 2007.

[30] M. F. Rios, C. M. G. Pajan, R. H. Galan, A. J. M. Sanchez, and I. G. Callado, "Synthesis and free radical scavenging activity of a novel metabolite from the fungus Colletotrichum gloeosporioides," Bioorganic \& Medicinal Chemistry Letters, vol. 16, pp. 5836-5839, 2006.

[31] S. S. Ali, N. Kasoju, A. Luthra et al., "Indian medicinal herbs as sources of antioxidants," Food Research International, vol. 41, no. 1, pp. 1-15, 2008. 

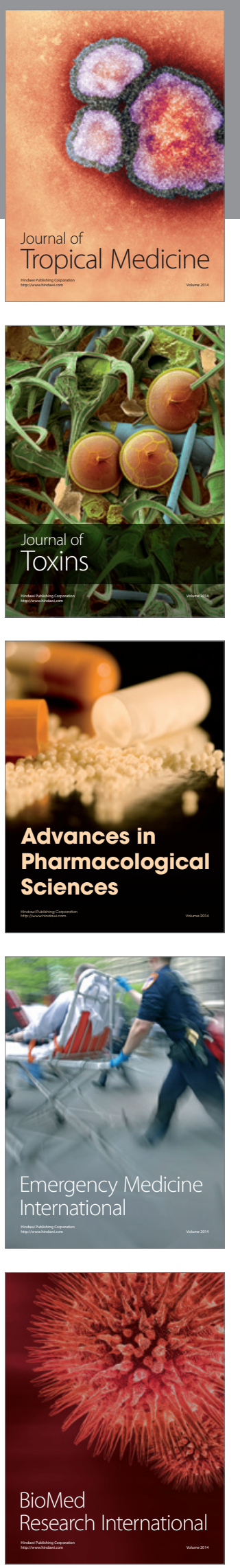
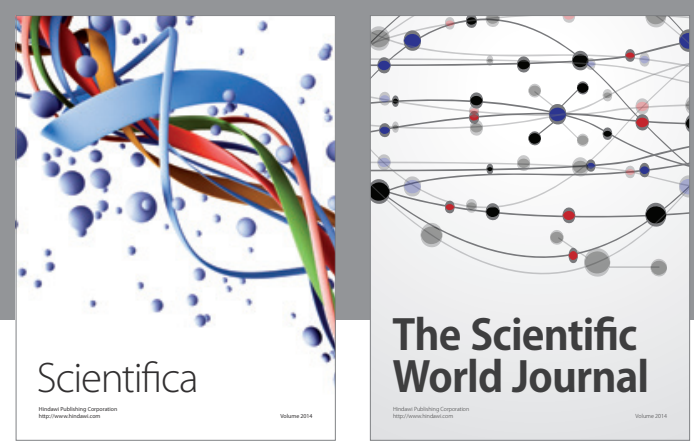

The Scientific World Journal
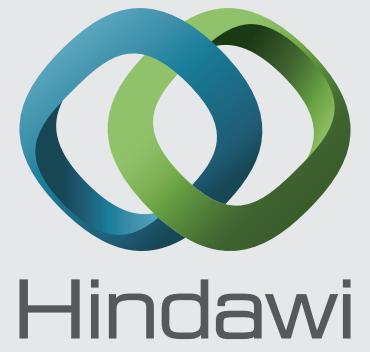

Submit your manuscripts at

http://www.hindawi.com
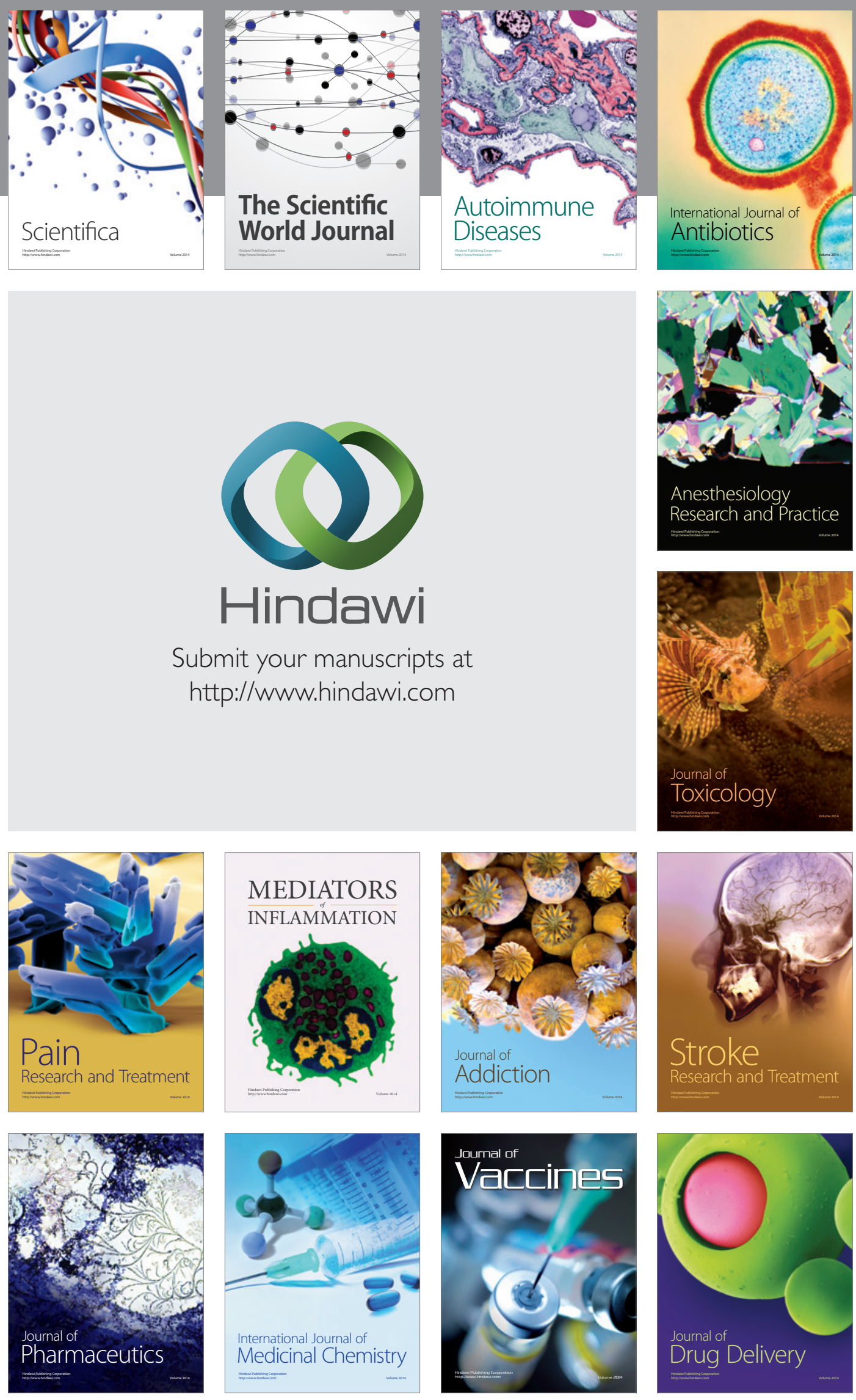